\title{
MERCADO REGULADO DE ÓRGÃOS: UMA POSSIBILIDADE CONTRA O TRÁFICO?
}

\author{
Maria de Fátima Freire de Sá ${ }^{1}$ \\ Lucas Costa de Oliveira ${ }^{2}$
}

\begin{abstract}
Resumo
O tráfico de órgãos humanos é uma preocupação global. A principal maneira de combater essa prática tem sido a sua criminalização. Apesar dos esforços jurídicos, o tráfico tem aumentado sua abrangência fomentando um rentável mercado negro que tem como centralidade a exploração de pessoas em situação de vulnerabilidade. A escassez de órgãos aliada à proibição de qualquer mercantilização de partes do corpo humano são fatores primordiais para o crescimento do tráfico. Assim, faz-se necessário investigar a possibilidade de um mercado regulado, lícito e ético de órgãos humanos. Um mercado que aumente a oferta de enxertos disponíveis para transplante e, consequentemente, enfraqueça o tráfico de órgãos. Para tanto, a partir de uma revisão de literatura, serão analisados os principais argumentos morais favoráveis e contrários a esse tipo de mercado. Ainda, serão estudados modelos de regulação propostos, em especial o vigente no Irã. A conclusão indica que um mercado regulado e ético de órgãos pode ser uma alternativa possível para combater o tráfico.
\end{abstract}

Palavras-chave: Mercado Regulado de Órgãos; Tráfico de Órgãos; Mercantilização do Corpo Humano; Bioética; Biodireito.

\section{INTRODUÇÃO}

O tráfico de órgãos humanos representa uma preocupação global. A principal maneira de combater essa prática tem sido a sua tipificação. Exemplo disso é o Convenio del Consejo de Europa sobre la lucha contra el tráfico de órganos humanos (2014), que tem como objetivo "a prevenção e a luta contra o tráfico de órgãos humanos mediante a tipificação como delito de certos atos." No mesmo sentido, a Espanha foi um dos primeiros países a tipificar o tráfico e o turismo de órgãos em seu Código Penal. Desde 2010, a legislação espanhola faz referência explícita ao tráfico de órgãos, com penas de até 12 anos de prisão. ${ }^{4}$ (ESPAÑA, 2016).

A escassez aliada à proibição de qualquer tipo de mercantilização de órgãos são fatores primordiais para o

\footnotetext{
${ }^{1}$ Doutora em Direito pela Universidade Federal de Minas Gerais. Professora no Programa de Pós-graduação stricto sensu em Direito da Pontifícia Universidade Católica de Minas Gerais. Coordenadora e Pesquisadora do Centro de Estudos em Biodireito CEBID.E-mail:mfatimasa@uol.com.br

${ }^{2}$ Mestrando em Direito Privado pela Pontifícia Universidade Católica de Minas Gerais. Membro do Centro de Estudos em Biodireito - CEBID. E-mail: lucascoliveira01@gmail.com

${ }^{3}$ Capítulo 1; Art. 10. Tradução nossa.

${ }^{4}$ Título VII BIS; Art. 177 BIS.
} 
aumento do tráfico. Ora, se não há órgãos disponíveis para todos, duas opções surgem: 1) optar pela legalidade, adequando-se ao sistema de transplante vigente; 2) optar pela ilegalidade, buscando meios escusos para a obtenção de enxertos.

Apesar do esforço para criminalizar o tráfico de órgãos, a prática vem crescendo. Estima-se que o mercado ilegal de órgãos movimenta cerca de um bilhão de dólares por ano, somente na China. (CARNEY, 2015). Na mesma direção, a Organs Watch indica, em uma avaliação conservadora, que cerca de dez mil rins são vendidos por ano. (SCHEPER-HUGHES, 2014). Desse modo, constatada a insuficiência da criminalização dessas condutas, faz-se necessária a entrada de outra argumentação no discurso. É importante perquirir sobre a possibilidade de um sistema que aumente a oferta de órgãos, sem que deixe de lado as preocupações éticas e legais que permeiam o debate. Um sistema que, dessa maneira, oponha-se ao tráfico de órgãos humanos.

Mesmo em países que são referências no sistema de doação de órgãos, como a Espanha, não foi possível eliminar a lista de espera de transplantes. (GHODS; SAVAJ, 2006, p. 1143). Assim sendo, a proposta deste artigo é analisar um sistema lícito, regulado e ético de doação de órgãos remunerada, ou, de maneira mais direta, um mercado regulado de órgãos humanos como possibilidade para aumentar a oferta de enxertos disponíveis para transplante e, consequentemente, combater o tráfico.

Para se atingir o objetivo proposto serão analisados os principais argumentos morais favoráveis e contrários a esse tipo de mercado, determinados a partir de uma revisão de literatura. Ainda, serão estudados modelos de regulação propostos por filósofos, bem como o modelo vigente no Irã.

\section{MERCADO REGULADO DE ÓRGÃOS: UMA QUESTÃO MORAL}

A relação entre direito e moral é complexa e admite variadas perspectivas. Ao longo da história do pensamento jurídico diversas correntes buscaram explicar o conceito de direito através dessa relação. Os jusnaturalista defendiam que apenas seria direito aquilo que fosse, anteriormente, moral. A validade do direito estava condicionada à validade moral. Os positivistas buscaram explicar o direito em sua separação absoluta da moral. Assim, nenhum defeito moral seria capaz de invalidar uma norma vigente. No chamado pós-positivismo, essa relação se mostra menos cristalina. O esforço reside em encontrar o locus normativo e argumentativo da moral no discurso jurídico. Por um lado, não se pode cair em uma metafísica absolutista como pretenderam os jusnaturalistas. Por outro, não se pode ficar atrelado a um relativismo valorativo como defenderam os positivistas.

Seja no discurso de justificação da norma (Günther; Habermas), ou na própria aplicação do direito (Alexy; Dworkin), a moral assume um papel de relevância na teoria contemporânea do direito. No caso de um mercado regulado de órgãos, a questão moral assume um papel ainda mais relevante. Isso ocorre porque dos argumentos para a criminalização dessa prática são predominantemente morais. É o que entende Stephen 
Wilkinson (2003, p. 103, tradução nossa):

Contudo, no contexto do presente capítulo, essa é uma distinção [entre direito e moral] que, em termos práticos, entra em colapso. $\mathrm{O}$ que eu quero dizer com isso é que, apesar de estar preocupado exclusivamente com argumentos e conceitos morais, minhas descobertas terão, inevitavelmente, implicações nessa área do direito. Isso porque, tendo em conta os substanciais benefícios práticos que um mercado comercial de órgãos humanos entregaria, $\mathrm{o}$ caso para a proibição legal deve, inevitavelmente, ser moral (e, quase certo, uma moral nãoutilitária). Consequentemente, ao avaliar criticamente as objeções morais à venda de órgãos, estarei também avaliando o caso para a proibição legal (ou pelo menos a parte mais importante desse caso). Se as objeções morais se mostrarem falhas, então não apenas o caso para a proibição legal estará minado, mas - dadas as vantagens práticas acima mencionadas - teremos um forte caso prima facie para a permissão (ou até encorajamento) de um mercado comercial de órgãos.

Em outras palavras, Wilkinson entende que em razão dos benefícios práticos que a comercialização de órgãos causaria - em especial o aumento da quantidade de enxertos disponíveis para transplante -, a razão para a proibição desse mercado deve ser de cunho moral. Destarte, identificando e analisando os argumentos morais favoráveis e contrários ao mercado regulado de órgãos será possível chegar não apenas a uma conclusão moral sobre a prática, mas também a uma conclusão legal para a permissão ou proibição desse mercado.

Antes, porém, é necessário realizar algumas observações. Os argumentos levantados serão analisados da seguinte maneira: em um primeiro momento serão apresentados do modo que seus defensores o fazem; em seguida serão apontadas algumas refutações. O leitor poderá ter a percepção que os argumentos contrários são refutados de maneira mais incisiva. Isso ocorre por duas razões. A primeira é que os argumentos favoráveis possuem um caráter mais pragmático e empírico, exigindo uma contraposição da mesma natureza - o que é mais complexo. A segunda é que os argumentos contrários são estudados e debatidos em uma proporção muito maior na literatura. A ideia é expor os argumentos do modo mais descritivo possível para, ao final, assumir posições. Também é necessário observar que muitos desses argumentos possuem como pano de fundo um mercado ilegal de órgãos, não sendo aplicados em um mercado regulado de órgãos. Contudo, em razão da importância e notoriedade dessas teses, também serão analisadas.

\section{ARGUMENTOS FAVORÁVEIS}

Quando o assunto em pauta é a mercantilização de órgãos, a argumentação volta-se, quase que exclusivamente, aos argumentos contrários a tal prática. Uma pesquisa na literatura demonstra que o debate perpassa pela afirmação ou refutação dos argumentos opostos ao mercado regulado de órgãos, não havendo uma dedicação similar em relação aos argumentos favoráveis. Uma hipótese para isso reside no fato de a criminalização dessa prática representar uma intromissão na esfera de liberdade das pessoas - um impedimento ao livre uso do corpo. Desse modo, qualquer tentativa de violação dessa esfera deveria suportar o ônus argumentativo. 
Afinal, se o ordenamento jurídico existe pela e para a pessoa humana, deve-se ter em conta que a tão propalada dignidade envolve, inexoravelmente, a capacidade que os indivíduos têm de construir projetos de vida para si. Nesse contexto, o corpo, como elemento indispensável para a existência da pessoa humana, deve ser inserido nesses projetos pessoais, passível, portanto, de manipulação e modificação. Assim, o eixo argumentativo deve deslocar-se do "por que permitir?" para o "por que proibir?". (LARA et al, 201 1, p. 2).

Apesar do enfoque nas razões desfavoráveis, é possível apontar alguns argumentos a favor de um mercado regulado, lícito e ético de órgãos. São argumentos predominantemente utilitários, que indicam razões pragmáticas para a permissão de tal mercado - embora não se restrinjam a esse tipo de argumentação. Importante deixar claro que não se trata de uma lista exaustiva.

\section{Aumento da oferta}

O aumento na oferta de órgãos disponíveis para transplante é conditio sine qua non para os demais argumentos, afinal, partiu-se da premissa de que a escassez de órgãos é um dos principais fatores para o aumento do tráfico, sendo necessário pensar em uma solução para o aumento da oferta. Um mercado regulado de órgãos deve ser capaz, portanto, de aumentar a quantidade de órgãos disponíveis para transplante. Trata-se, sobretudo, de uma questão prática e empírica.

A experiência iraniana com um modelo de doação de rins regulada e remunerada merece ser citada. As especificidades do modelo iraniano serão analisadas mais adiante. O que importa indicar nesse ponto é que tal modelo aumentou consideravelmente a oferta de órgãos para transplante. Em 1988 um sistema remunerado e regulado de doação de rins foi adotado no Irã. Como resultado, a oferta aumentou de tal maneira que em 1999 não havia mais listas de espera para transplantes renais no país. Até o final de 2005, um total de dezenove mil seiscentos e nove transplantes renais haviam sido realizados. (GHODS; SAVAJ, 2006, p. 1137).

Por outro lado, o clássico estudo realizado pelo sociólogo britânico Richard Titmuss (1997) a respeito da doação de sangue é um bom ponto de partida. O sociólogo comparou o sistema de doação de sangue vigente no Reino Unido, onde todo o sangue disponível para transfusão é doado por voluntários não remunerados, e o sistema vigente nos Estados Unidos, onde parte do sangue disponível para transfusão é doado por voluntários não remunerados, e outra parte é comprada por bancos comerciais de pessoas que se dispõem a vender seu sangue para receber uma remuneração.

No período do estudo a demanda por sangue havia aumentado consideravelmente em razão das novas técnicas de cirurgia, bem como por razões sociais e econômicas. No Reino Unido, onde os doadores não eram remunerados, o número de doações cresceu o suficiente para cobrir a nova demanda. Nos Estados Unidos, por outro lado, onde parte era obtida através do mercado, a demanda não foi coberta, gerando graves problemas de escassez. (SINGER, 1973, p. 314-315).

Após discorrer sobre aspectos éticos e pragmáticos, Richard Titmuss conclui que o sistema britânico de vol.10, nº. 01, Rio de Janeiro, 2017.pp. 434-453 
coleta de sangue funciona melhor que o sistema americano, em termos econômicos e práticos. Segundo o sociólogo, o sistema americano leva à escassez crônica, desperdício de sangue, custos mais altos e maior risco de contaminação. (SANDEL, 2014, p. 121).

A partir da experiência empírica e específica realizada no Irã, é possível considerar que a oferta de órgãos para transplante tende a aumentar consideravelmente a partir da abertura e regulação desse mercado. Contudo, o estudo realizado sobre o sistema de doação de sangue relativiza a conclusão que um mercado regulado aumenta, inevitavelmente, a oferta de produtos. Resta saber, portanto, se a experiência iraniana pode ser exportada para outros países.

\section{Enfraquecimento do tráfico}

O mercado negro, entendido como o conjunto de atividades realizadas à margem do controle estatal, surge a partir da proibição, restrição ou imposição de certa prática. Essa é a razão pela qual se pode dizer que a história das atividades ilegais é tão antiga quanto à das leis. (MACKEEY; ROSSEAU, 2015, p. 185).

Vários são os setores englobados pelo conceito de mercado negro, em especial o tráfico de produtos ou serviços proibidos e o tráfico de produtos ou serviços regulamentados. No primeiro caso pode-se exemplificar com o tráfico de drogas e o tráfico de órgãos; já no segundo caso tem-se como exemplo o contrabando de cigarros e as contrafações de obras. (MACKEEY; ROSSEAU, 2015, p. 186).

A criação de um mercado regulado e lícito de órgãos teria como consequência o enfraquecimento - ou até mesmo a eliminação - do mercado negro exercido na forma de tráfico. Nesse sentido, Ejan Mackeey e Stéphane Rosseau (2015, p. 196).

O mercado negro não parece criar uma dependência irreversível. Quando são afastadas as proibições, assim [como] as restrições ou imposições excessivas que dão origem ao mercado negro, é recriado o mercado oficial. Se a experiência dos Estados Unidos da América, depois da Lei Seca pode servir de exemplo, esse mercado tem as configurações do mercado regulamentado - que existia anteriormente. A mudança tem muitos efeitos desejados melhora da qualidade do produto, melhor conhecimento dos seus efeitos, menores preços, taxas e impostos recebidos normalmente, redução da criminalidade e da necessária repressão para contê-la.

Importante destacar que a regulação deve ser realizada de maneira competente, sempre atenta à eliminação dos possíveis danos, coerção, objetificação e exploração das pessoas envolvidas. Outro aspecto fundamental é que haja uma remuneração suficiente e justa para aqueles que se dispuserem a vender seus órgãos, já que a regulação fecha as portas para o tráfico de serviços proibidos, mas sempre existe o perigo do tráfico de serviços regulamentados. $\mathrm{O}$ que se pretende dizer é que uma regulação em que não haja uma contraprestação razoável também abre as portas para um mercado negro.

De qualquer forma, é possível concluir que a legalização e regulação de um mercado de órgãos tem como 
consequência a diminuição do tráfico. Contudo, esse é um argumento que não pode ser analisado de maneira isolada, mas em conjunto com as questões éticas e morais que permeiam o debate.

\section{Autonomia}

Em uma perspectiva moral (e também jurídica), o argumento da autonomia se destaca no debate sobre um mercado regulado de órgãos. Como já escrito anteriormente, pensar sobre o princípio da autonomia é uma tarefa em constante tensão: autonomia e heteronomia, privado e público, liberdade e alteridade, $E u$ e $T u$. Ter autonomia é ter a possibilidade de desenvolver uma pessoalidade, de viver sob a própria percepção de vida boa, é emergir como ser pensante, dialógico, biográfico, humano. Assim, a concepção de autonomia se entrelaça à concepção de pessoa - criativa, livre, em eterna construção. (OLIVEIRA, 2016, p. 249).

Assim, pensa-se em uma autonomia que não apresente uma faceta absoluta, representação única da liberdade inabalável, como pensado na modernidade; nem mesmo descambe para um coletivismo que acabe com a sua própria razão de ser, como já se pensou na antiguidade. A autonomia deve conformar-se em suas dimensões de liberdade, alteridade e dignidade.

Liberdade indica o espaço conquistado para o exercício de uma pessoalidade autônoma. Pode ser positiva ou negativa: a primeira trata-se da capacidade de escolher, sem constrangimento, entre fazer uma coisa ou outra. A segunda pressupõe a mínima intervenção nas decisões e ações da pessoa. Necessário evidenciar que não existe liberdade sem responsabilidade, afinal, como já ensinou João Baptista Villela (1982, p. 32), “o homem só é feliz à condição de ser livre. Só é livre, quando responsável. E só é responsável se os motivos de sua conduta estão dentro e não fora dele".

Alteridade significa pensar que a autonomia apenas existe em face do outro. Se alguém é autônomo, somente o é perante os demais. É pensar a pessoa como ser social, dialógico, intersubjetivo.

O conceito de dignidade, no contexto de uma sociedade cada vez mais plural e complexa, apenas pode caminhar rumo à autonomia. Não cabe a qualquer entidade superior (e.g. Estado, Igreja) impor um substrato axiológico a esse conceito que deve, necessariamente, permanecer em aberto. É a partir dessa abertura que cada pessoa tem a possibilidade de construir sua dignidade a partir da própria percepção de vida boa. (OLIVEIRA, 2016, p. 261). Dignidade, nesse sentido, "é ser o que quiser. A vida, nesse sentido, adquire significado de acordo com os referencias valorativos da própria pessoa, enquanto ser autônomo, e não por imposições externas". (LARA et al, 2011, p. 5).

É nessa perspectiva que se pensa em uma autonomia corporal ou livre uso do corpo. A partir dessa construção, cabe a cada pessoa construir sua pessoalidade a partir da sua relação com o próprio corpo. Não caberia a uma entidade externa apontar, de antemão, quais são as possibilidades de manifestação da pessoa em sua 
corporeidade. Nesse sentido, "estabelecer, de pronto, que a venda de órgãos é contrária à dignidade da pessoa humana significa limitar as próprias opções de ser pessoa, as quais podem passar, inclusive, por escolhas consideradas controversas pela maioria da sociedade". (LARA et al, 2011, p. 6). É o que também entende Julian Savulesco (2003, p. 139-140, tradução nossa):

As pessoas têm direito de tomar a decisão de vender uma parte do corpo. Se devemos ser permitidos a vender nosso trabalho, por que não vender os meios para esse trabalho? Se devemos ser permitidos a arriscar causar dano ao nosso corpo por prazer (ao fumar ou esquiar), por que não por dinheiro que usaremos para realizar outros bens na vida? Proibir um mercado de órgãos é, paradoxalmente, restringir o que as pessoas podem fazer com suas próprias vidas.

Dessa maneira, um mercado regulado de órgãos humanos pode representar um meio para a afirmação da autonomia das pessoas, desde que esteja em conformidade com as dimensões apontadas.

\section{Outros argumentos}

Poder-se-ia ainda levantar outros argumentos a favor de um mercado regulado de órgãos humanos.

A venda de substâncias do corpo humano é um argumento relevante. Já é possível encontrar países que permitem a compra e venda de sangue, esperma, óvulos e tecidos em maior ou menor grau, como os Estados Unidos. Qual seria, portanto, o óbice para a compra e venda de órgãos? A principal resposta aponta para a irreversibilidade do objeto, já que órgãos não são renováveis. Contudo, como adverte Gerald Dworkin, permite-se que pessoas façam mudanças permanentes no corpo, como a esterilização. Desse modo, entende o filósofo que se trata de respeitar a autonomia corporal dos indivíduos. (DWORKIN, 1994, p. 156).

O paternalismo é apontado como uma crítica à proibição de um mercado regulado de órgãos. Trata-se, sobretudo, da pretensão de proteger as pessoas de suas próprias decisões. Julian Savulesco (2003, p. 139, tradução nossa) argumenta que "impedir [as pessoas] de tomarem essas decisões, é julgar que elas são incapazes de tomar decisões sobre o que é melhor para as próprias vidas. É paternalismo em sua pior forma." Gerald Dworkin (1994, p. 157, tradução nossa) manifesta a mesma crítica: "parece-me paternalismo ao extremo, dada essa injustiça [distributiva], negar às pessoas pobres escolhas que elas entendem aumentar o seu bem-estar." Assim sendo, fazse necessário indagar se tal restrição não seria de um paternalismo ultrajante em um momento de consolidação do Estado Democrático de Direito.

O argumento da cadeia de produção indica que todos os envolvidos no processo de doação de órgãos são remunerados, menos o doador. O cirurgião, sua equipe, o hospital, as empresas que fornecem os materiais e medicamentos. Tratar-se-ia, então, de uma hipocrisia. (ERIN; HARRIS 2003, p. 137-138). 


\section{ARGUMENTO CONTRÁRIOS}

Como já mencionado, a atenção dada aos argumentos contrários à mercantilização dos órgãos é consideravelmente maior. A diversidade e quantidade de razões levantadas contra o mercado de órgãos impossibilita uma análise aprofundada de cada uma dessas razões. Atento a esse problema, Stephen Wilkinson (2003, p. 103) restringiu seu estudo em cinco objeções à venda de órgãos: (1) Que essa prática causaria danos aos vendedores; (2) Que acabaria com a promoção do altruísmo gerado pela doação; (3) Que o consentimento seria, em muitos casos, inválido; (4) Que os vendedores seriam coagidos a vender seus órgãos; (5) Que os vendedores seriam explorados.

Optou-se por seguir a orientação restritiva de Wilkinson, apesar da escolha das objeções terem sido parcialmente distintas. Após uma pesquisa na literatura sobre o tema, entendeu-se que outros argumentos confrontam o mercado regulado de órgãos de maneira mais efetiva. São estes: exploração, objetificação, consentimento, injustiça e sacralidade do corpo. Novamente, destaca-se que não se trata de uma lista exaustiva.

\section{Exploração}

Uma vez regulado o mercado de órgãos, é correto pensar que a prática recairia sobretudo sobre as pessoas de baixa renda, ocasionando situação de exploração.

Inicialmente é necessário compreender o que significa explorar alguém. A exploração pode ser entendida em um sentido não-moral e em um sentido moral. No primeiro sentido, não há nenhum tipo de normatividade ou valoração, sendo um conceito neutro. Significa utilizar algum recurso, oportunidade ou talento (e.g. exploração de minério de ferro). O segundo sentido, por sua vez, é mais complexo e possui duas facetas: o uso indevido e a disparidade de valor. $\mathrm{O}$ uso indevido ${ }^{5}$ indica uma maneira de agir que é contrária à sua natureza, ao passo que a disparidade de valor indica uma desproporção na distribuição dos benefícios envolvidos na troca de bens e serviços. (WILKINSON, 2003, p. 9-15). Assim sendo, quando se fala que um mercado de órgãos causaria a exploração dos pobres, pode-se querer dizer que essa prática motivaria um uso indevido dessas pessoas ao, por exemplo, tratá-las como meros objetos; ou que essa prática promoveria uma disparidade de valor, na medida em que a venda de órgãos seria realizada por preços injustos. ${ }^{6}$

Acontece que os pobres já são explorados cotidianamente: são sujeitos a trabalhos com maiores riscos e menores remunerações, possuem menos possibilidades e alternativas para atingirem seus objetivos. A proibição da venda de órgãos pode representar uma dupla injustiça. Seria como dizer a essas pessoas: "Você não pode ter o

${ }^{5}$ Nota-se que nem todo uso é indevido, como no caso do aluno que se utiliza de sua professora para aprender. vol.10, no. 01, Rio de Janeiro, 2017.pp.434-453 
que a maioria das pessoas têm e não vamos permitir que você faça o que quiser para conseguir essas coisas." (SAVULESCO, 2003, p. 139, tradução nossa). É certo que o ideal seria um mundo onde ninguém tivesse que vender seus órgãos para ter as mesmas chances que as outras pessoas, contudo não é o mundo em que se vive.

Nesse sentido, argumenta-se que um mercado regulado geraria um maior leque de opções para as pessoas de baixa renda - porquanto nem o Estado, nem a sociedade trouxeram alternativas efetivas para o aumento de oportunidades. Não haveria como um mercado desse tipo prejudicar as pessoas, na medida em que apenas traria mais possibilidades de escolha.

Contra esse argumento, Simon Rippon (2014, p. 145-150) demonstra que nem sempre mais opções geram melhores condições. Trata-se de contra-argumento complexo, que não cabe ser explanado em toda sua extensão nesse espaço. Em síntese, a principal razão é que adicionar a opção de vender um órgão causaria uma pressão nas pessoas de baixa renda para realizar a venda - diferente e mais grave que a pressão familiar envolvida no processo de doação. Essa possibilidade de escolha, por si só, acarretaria um dano a essas pessoas.

É verdade que a permissão de um mercado regulado de órgãos atingiria predominantemente a população de baixa renda, afinal aqueles que possuem outras alternativas dificilmente se submeteriam ao mercado. Exemplo disso é o caso iraniano, onde 84\% dos doadores são pobres. (GHODS; SAVAJ, 2006, p. 1140). Contudo, é necessário fazer algumas observações. A primeira é que essas pessoas já são exploradas em sua vivência diária. A segunda é que não existem ações suficientes para eliminar essa situação de desigualdade e exploração. A terceira é que a vedação de um mercado regulado de órgãos causa uma maior exploração dos pobres, já que são levados para o âmbito do mercado negro.

Dessa maneira, é possível pensar em duas alternativas contra a exploração dos pobres frente a um mercado de órgãos. A primeira, mais desejável, porém utópica, é a erradicação das desigualdades e da pobreza, possibilitando mais alternativas para essas pessoas. A segunda, mais realista, porém controversa, é a regulação de um mercado de órgãos para que a prática seja realizada de maneira ética e legal.

\section{Objetificação}

$\mathrm{O}$ argumento da objetificação indica que tratar pessoas como objetos é moralmente errado. Dessa forma, ao atribuir valor pecuniário aos órgãos, um mercado regulado de órgãos estaria tratando pessoas como meros objetos, ignorando sua intrínseca dignidade.

Trata-se de uma objeção intimamente ligada ao pensamento de Immanuel Kant. A objetificação pode

\footnotetext{
${ }^{6}$ Outro exemplo pode ser retirado da prostituição. Quando se fala que a prostituição causa a exploração das mulheres, pode-se dizer que: (1) as mulheres são tratadas como objetos sexuais (uso indevido); (2) as mulheres são mal remuneradas pelo serviço que prestam (disparidade de valor). In: WILKINSON, 2003, p. 12.
} 
ocorrer de duas maneiras. ${ }^{7}$ Uma é relacionada ao Imperativo Prático de Kant: "Age de tal maneira que uses a humanidade, tanto na tua pessoa como na pessoa de qualquer outro, sempre e simultaneamente como fim e nunca simplesmente como meio". (KANT, 2007, p. 69). A outra é relacionada à distinção entre preço e dignidade realizada por Kant: "No reino dos fins tudo tem ou um preço ou uma dignidade. Quando uma coisa tem um preço, pode-se pôr em vez dela qualquer outra como equivalente; mas quando uma coisa está acima de todo o preço, e, portanto, não permite equivalente, então tem ela dignidade". (KANT, 2007, p. 77). Dessa forma, a objetificação é apontada como gênero que tem como espécie a instrumentalização e a comodificação. (WILKINSON, 2003, p. 29).

A instrumentalização está relacionada ao que foi escrito sobre a exploração no sentido do uso indevido, afinal, quando se instrumentaliza uma pessoa, há o uso indevido desta (o uso como mero meio). Sobre esse ponto, uma observação é importante. Kant não conclui que é proibido tratar pessoas como meio, mas afirma que existe uma obrigação de tratá-las sempre, simultaneamente, como fim. Essa afirmação indica que é possível tratar pessoas como um meio, desde que as trate também como um fim. Não se trata, portanto, de uma relação exclusiva entre meio e fim, mas integrativa. Quando uma pessoa realiza a doação voluntária e gratuita dos seus órgãos, ela é tratada como um meio para a salvação da vida de outra pessoa, contudo é também tratada como fim, já que sua ação foi autônoma. No caso em estudo, portanto, a grande questão é saber se um mercado regulado de órgãos consegue tratar as pessoas como meio e fim ao mesmo tempo. Stephen Wilkinson (2003, p. 37, tradução nossa) esclarece o pensamento de Immanuel Kant nesse sentido:

Seu pensamento é que quando nos tornamos focados no valor instrumental da pessoa, na sua utilidade para nós, temos a tendência de desconsiderar o fato que ela é um ser autônomo que merece respeito. Em outras palavras, pensar na pessoa em termos de uso nos encoraja a negligenciar o fato que ela é não apenas para nosso uso, mas também um fim-em-si-mesmo.

Em um sentido comum e descritivo, comodificação se refere à prática social de tratar coisas como commodities, ou seja, como propriedade que pode ser comprada, vendida ou alugada. (WILKINSON, 2003, p. 44). Em um sentido moral, comodificação se refere à prática social de tratar pessoas como commodities, atribuir características de mercado às pessoas, ou, como Kant estabelece, atribuir preço a quem deve-se atribuir dignidade. Nessa direção, o estabelecimento de um mercado regulado de órgãos afetaria esse princípio, na medida em que atribui preço a uma parte do corpo humano.

É possível problematizar essa objeção de diversas maneiras. A primeira maneira é questionar se não é possível que algo tenha preço e ao mesmo tempo dignidade. Ora, o trabalho é uma forma de mercantilizar a vida

\footnotetext{
${ }^{7}$ Nussbaum aponta sete maneiras de objetificar uma pessoa: (1) Instrumentalidade: a pessoa é tratada como uma simples ferramenta ou meio para o objetivo de outrem; (2) Negação de autonomia: a autonomia da pessoa não é reconhecida ou respeitada; (3) Inércia: a pessoa é tratada como se não tivesse vontade ou atividade; (4) Fungibilidade: a pessoa é tratada como intercambiável; (5) Violabilidade: a integridade corporal da pessoa não é respeitada; (6) Propriedade: a pessoa é tratada como domínio de outrem; (7) Negação de subjetividade: as experiências da pessoa não são reconhecidas. Stephen Wilkinson entende que essas sete maneiras de objetificação podem ser extraídas dos dois princípios expostos de Kant. In: WILKINSON, 2003, p. 28. vol.10, no. 01, Rio de Janeiro, 2017.pp.434-453 443
} 
humana. Convencionou-se que o que é dotado de preço é a capacidade de trabalho da pessoa - e não a pessoa em si. Trata-se de uma abstração para evitar a conclusão de que a pessoa é dotada de um preço. De qualquer modo, isso não impede que a pessoa também seja dotada de dignidade. É lugar comum a expressão que diz que "o trabalho dignifica o homem”. Assim, ao que tudo indica, é possível que preço e dignidade adjetivem o mesmo substantivo.

Ainda, é possível questionar se a precificação de parte do ser humano causa a total objetificação da pessoa. É possível vender o sangue, esperma, óvulos, cabelo, sem que isso indique que a pessoa seja totalmente uma mercadoria. Portanto, a venda de órgãos não tornaria a pessoa uma mercadoria por completo.

Outro problema é o conceito de dignidade utilizado por Kant. Em uma sociedade pós-metafísica é possível utilizar-se de um conceito metafísico? A quem cabe estabelecer o que é dignidade? A dignidade não pode ser um conceito a priori sob pena de excluir da sua esfera diversas maneiras de manifestação da pessoalidade. Desse modo, a dignidade deve ser um conceito aberto, em eterna construção por cada pessoa.

Por fim, interessante é o diagnóstico de Zygmunt Bauman a respeito da transformação das pessoas em mercadorias. Para o sociólogo polonês, o indivíduo da sociedade de consumidores é, também, a própria mercadoria. Esse indivíduo não nasce pronto, mas deve fazer de si mesmo (e não apenas tornar-se) uma mercadoria vendável. Trata-se de um processo de auto fabricação em que o próprio mercado fornece as ferramentas necessárias. É nesse processo de objetificação do ser humano que as barreiras entre sujeito e objeto se entrelaçam. (OLIVEIRA, 2015, p. 172). Nas palavras de Bauman (2008, p. 20).

Na maioria das descrições, o mundo formado e sustentado pela sociedade de consumidores fica claramente dividido entre as coisas a serem consumidas e os que as escolhem; as mercadorias e seus consumidores: as coisas a serem consumidas e os seres humanos que as consomem. Contudo, a sociedade de consumidores é o que é precisamente por não ser nada desse tipo. O que a separa de outras espécies de sociedade é exatamente o embasamento e, em última instância, a eliminação das divisões citadas acima. Na sociedade de consumidores, ninguém pode se tornar sujeito sem primeiro virar mercadoria, e ninguém pode manter segura sua subjetividade sem reanimar, ressuscitar e recarregar de maneira perpétua as capacidades esperadas e exigidas de uma mercadoria vendável.

A partir dos contrapontos levantados é possível relativizar a objeção da comodificação. Percebe-se que a oposição pautada por esse argumento se baseia em uma noção metafísica de dignidade, bem como está relacionada com escolhas culturais e sociais, já que outros aspectos e partes do ser humano podem ser abarcados pela esfera do mercado.

\section{Consentimento}

Outro argumento aventado é que não seria possível obter um consentimento válido das pessoas que optassem por vender seus órgãos. Isso ocorreria porque as pessoas seriam coagidas a realizar essa ação por não possuírem outras alternativas. 
O primeiro ponto a ser esclarecido é sobre o conceito de consentimento, ou, em outras palavras, quando um consentimento pode ser considerado válido. Um bom parâmetro é a utilização da construção do consentimento informado (ou também consentimento livre e esclarecido) desenvolvido pela bioética. Nessa perspectiva, diz-se que um consentimento é informado quando: (1) o paciente está esclarecido do diagnóstico, do tratamento mais adequado a se implementar e de seus efeitos positivos e negativos. A informação deve ser transmitida de maneira clara e abrangente, em um processo dialógico; (2) o paciente possui discernimento para a tomada de decisões. Isso significa estabelecer diferença, distinguir, fazer apreciação; (3) o paciente não está condicionado por fatores externos à manifestação de vontade. Assim, a vontade deve ser livre, sem qualquer tipo de vício - seja social ou de consentimento. (SÁ; NAVES, 2015, p. 108-109). Em síntese: "Consentimento significa uma decisão voluntária, sem coação, tomada por uma pessoa suficientemente competente ou autônoma, com base em informação e deliberação adequadas, para aceitar ou rejeitar algum curso de ação proposta. " (GILLON apud WILKINSON, 2003, p. 76, tradução nossa). Dessa maneira, é possível concluir que um consentimento válido deve ser voluntário (sem coerção), competente (discernido), e informado (esclarecido).

Desses requisitos o que é mais problemático para o caso do mercado regulado de órgãos é a voluntariedade, representado na ausência de coerção. Seria complicado pensar em uma objeção genérica pautada na falta de discernimento dos vendedores (o fato de uma pessoa querer vender seus órgãos a torna incapaz?), ou na ausência de informação (uma pessoa pode ser plenamente esclarecida e informada de todos os benefícios e riscos e, mesmo assim, optar por vender seus órgãos). É necessário ter em consideração que nenhuma ação é absolutamente livre, sem a influência de outros fatores, afinal o ser humano é um ser cultural, dialógico, nãohermético. Portanto, é preciso diferenciar os condicionantes internos e externos. Os primeiros são aqueles que influenciam psicologicamente a pessoa - como a pressão cultural e social. Já os segundos são exercidos de maneira externa ao indivíduo - um bom exemplo são os vícios de consentimento. ${ }^{8}$ (SÁ; NAVES, 2015, p. 109).

Um paralelo pode ser traçado com a doação "gratuita" de órgãos. Caso um pai esteja com sérios problemas renais, tendo um filho compatível, certamente existe uma forte pressão familiar para a doação de órgãos. Contudo, se a ação for voluntária e informada não há quem levante a objeção da coerção. Seria o caso do mercado regulado de órgãos diferente? O único fator que parece ser distinto é a pressão interna e psicológica, que no primeiro caso é exercida pela família, e no segundo pode ser uma pressão social ou pessoal.

Pensar que o fato de uma pessoa querer ser remunerada pela doação dos seus órgãos a torna incapaz de consentir, trata-se de um argumento frágil. A pobreza não gera, por si só, incapacidade. O pobre é pressionado a trabalhar em empregos mal remunerados ou com mais riscos, e nem por isso consideram o seu consentimento inválido. Assim, sendo o consentimento voluntário, informado e discernido, é possível considerá-lo válido -

${ }^{8}$ No direito civil brasileiro os vícios do consentimento são: erro, dolo, coação, estado de perigo e lesão. vol.10, nº. 01, Rio de Janeiro, 2017.pp.434-453 
inclusive no contexto de um mercado regulado de órgãos.

\section{Injustiça}

Uma objeção relevante é a questão da injustiça. Aqui, trata-se da (in) justiça distributiva, aquela que diz respeito a como uma sociedade ou grupo deve alocar os recursos e os produtos escassos entre indivíduos com necessidades e pretensões conflitantes. (FLEISCHAKER, 2004, p. 1). A preocupação reside no fato de que estabelecido um mercado de órgãos, apenas os ricos teriam a capacidade financeira de comprar os enxertos e, consequentemente, apenas os pobres venderiam. Assim, o produto escasso (órgão), seria distribuído para quem pagasse mais (ricos), deixando de lado a necessidade - muitas vezes maiores - das outras pessoas (pobres).

O ponto referente à venda de órgãos pelas pessoas de baixa renda já foi tratado na seção sobre a exploração, para onde remete-se o leitor. Sobre a questão distributiva, algumas considerações podem ser feitas. A primeira consideração trata-se de uma constatação: o sistema médico geral já é baseado na capacidade de pagamento - e em um mundo capitalista, poucas coisas não o são. A segunda, trata-se do fato de que a maioria dos transplantes são pagos pelas seguradoras públicas e privadas de saúde. (DWORKIN, 1994, p. 158).

Não obstante às considerações aventadas, uma outra é suficiente para enfraquecer de maneira incisiva essa preocupação. Um mercado de órgãos regulado de maneira ética e legal é capaz de se comprometer com a justiça distributiva. Uma opção é, por exemplo, estabelecer que os órgãos apenas podem ser vendidos para um único comprador (provavelmente o Estado), que deverá adotar um esquema de distribuição equânime, atento às necessidades e prioridades - como adotado no Irã. (DWORKIN, 1994, p. 157).

De mais a mais, a injustiça na distribuição de recursos já acontece de certa forma. $\mathrm{O}$ mercado negro distribui os recursos àqueles dispostos a pagar mais pelo bem, sendo possível até mesmo se falar em um turismo de órgãos. Assim, em um contexto de vedação do mercado de órgãos, quem tem condições financeiras é quem adquire a mercadoria, também sendo uma forma de injustiça distributiva.

\section{Sacralidade do corpo}

O corpo humano representa um símbolo cultural. No contexto de uma sociedade ocidental, moldada sob forte influência do cristianismo, o corpo é ainda reconhecido como algo sagrado. Nesse ponto, argumenta-se que qualquer tipo de mercantilização do ser humano o transforma "em um produto, violando a soberania de Deus e a 'intrínseca santidade da vida'. (NELKIN; ANDREWS, 1998, p. 36, tradução nossa).

Mas o que se quer dizer, realmente, quando se fala em sacralização? José Luiz Quadros de Magalhães, a partir dos estudos de Giorgio Agambem, indica um caminho. A sacralização seria entendida "como mecanismo de subtração do livre uso das pessoas as palavras e seus significados; coisas e seus usos; pessoas e sua significação 
histórica”. (MAGALHÃES, 2015, p. XVII).

Sacralizar significa retirar algo do livre uso e do comércio das pessoas, sendo uma forma de poder e dominação. O que é consagrado aos deuses não pode ser usufruído pelas pessoas. Lado outro, profanar é restabelecer o sacralizado ao livre uso de todas as pessoas. É nesse sentido que se fala que a função da religião seria a de separação, estabelecendo uma esfera intangível ao homem.

Contudo, não é somente no âmbito da religião propriamente dita que é possível se falar em sacralização. Adverte Magalhães (2015, p. XIX):

O capitalismo de mercado é uma grande religião que se afirma com a sacralização do mercado e da propriedade privada. As discussões que ocorrem na esfera econômica são encerradas com o recurso ao mito para impor uma ideia sacralizada a toda a população. No espaço religioso do capitalismo não há espaço para racionalidade discursiva, pois qualquer tentativa de questionar o sagrado é sacrilégio.

Entre a sacralização religiosa e a sacralização mercantil, emerge o debate sobre um mercado regulado de órgãos. Por um lado, a vedação de tal prática pode representar uma sacralização, segregação indevida do uso do corpo pelas pessoas, por outro, pode representar a colonização do mundo da vida pelo mercado, sendo a única coisa sagrada o capital.

Mas, entre extremos tão conflitantes, é possível encontrar uma solução razoável? A resposta consiste em dessacralizar o discurso, dessacralizar o corpo. A argumentação deve ser livre, dialógica, dessacralizada. Em um ambiente secularizado, o sagrado não pode integrar no discurso como algo absoluto, imutável. Afinal, "a corporeidade não é estática, ao contrário, é um processo dinâmico de construção de identidade". (LARA et al, 2011, p.3).

O corpo é sagrado, mas já se admite piercing, tatuagem. O corpo é sagrado, mas já se admite suicídio assistido e eutanásia. O corpo é sagrado, mas já se admite a gratuita disposição dos órgãos. O corpo é sagrado, mas já se admite o aborto. O corpo é sagrado ou sagrado é fazer o que quiser com o próprio corpo?

\section{Outros argumentos}

No espaço de um artigo seria impossível tratar de todos os argumentos contrários ao mercado de órgãos de maneira detida. Não obstante, outros argumentos possuem relevância e serão expostos brevemente.

O argumento do dano diz que a venda de órgãos seria errada porque submeteria os vendedores a dores e riscos desnecessários, sendo, portanto, uma prática danosa. O primeiro contraponto é que os riscos são, empiricamente, baixos. $\mathrm{O}$ transplante de rim, por exemplo, tem uma taxa de mortalidade de apenas 0,03\%. O segundo contraponto é que a proibição de um mercado regulado de órgãos causa maiores danos: ambiente sujo, precário, sem infraestrutura; médicos sem experiência; ausência de medicamento. Por fim, o argumento decisivo é que em um mercado regulado de órgãos, os riscos serão os mesmo da já aceita prática de doação de órgãos. 
(WILKINSON, 2003, p. 108).

Richard Titmuss, no já mencionado The Gift of Relationship, conclui que o sistema americano remunerado de doação de sangue tem como consequência a diminuição do espirito de altruísmo presente na sociedade. Desse modo, um sistema remunerado de doação de órgãos teria o mesmo efeito, o que seria ruim. Contudo, se um sistema remunerado aumenta a quantidade geral de órgãos disponíveis para transplante quando comparado com um sistema altruístico, seria ainda um argumento relevante? Além disso, cabe questionar se um sistema remunerado impediria que as pessoas continuassem doando seus órgãos altruisticamente.

Michael Sandel (2014, p. 110) resume as objeções contra a venda de órgãos em dois argumentos: a equanimidadee a corrupção.

É verdade que o dinheiro pode comprar um rim sem comprometer seu valor. Mas será que os rins devem ser comprados e vendidos? Os que acham que não costumam levantar dois argumentos: afirmam que esses mercados exploram os pobres, cuja decisão de vender o rim pode não ser realmente voluntária ( $\mathrm{o}$ argumento da equanimidade). Ou então sustentam que esses mercados promovem uma visão degradante e coisificante da pessoa humana, como se fosse uma coleção de partes avulsas (o argumento da corrupção).

A objeção da equanimidade é pautada em um vício de consentimento lato sensu. Esse argumento aponta para as consequências da mercantilização de todos os aspectos da existência humana, aproximando-se, portanto, de um argumento utilitarista. Assim sendo, em uma situação ideal, onde todos pudessem consentir de maneira efetivamente livre, sem nenhum tipo de coerção, a prática comercial não sofreria objeção. Qualquer coisa poderia ser comprada e vendida. Por outro lado, a objeção da corrupção indica um defeito intrínseco, apontando para um argumento categórico. Dessa maneira, vender coisas de caráter existencial e fundamental seria degradante por si só. (OLIVEIRA, 2015, p. 171).

Por fim, importante trazer à baila a posição de Stefano Rodotà. O jurista italiano aponta o surgimento de um mercado de direitos [...] em que os tradicionais direitos econômicos, inscritos na liberdade de comércio, se mesclam com direitos fundamentais que, alheios à lógica de intercâmbio, buscam também uma infinita possibilidade de expansão". (RODOTÀ, 2010, p. 74, tradução nossa). Em suma, entende que direitos da personalidade devem permanecer fora da esfera de mercado, pois a mercantilização de tais direitos seria uma afronta à liberdade e à dignidade das pessoas - e nada pode justificar uma existência sem liberdade e dignidade. Os direitos da personalidade seriam, portanto, inegociáveis (mesmo para os seus titulares), superando qualquer noção patrimonial da pessoa humana.

\section{UMA POSSIBILIDADE CONTRA O TRÁFICO}

Entre a total proibição e o livre mercado existe uma grande variedade de opções para a regulação de um 
mercado de órgãos. ${ }^{9} \mathrm{O}$ modelo que se escolheu estudar representa uma alternativa que tem como principal característica o enfraquecimento (ou até anulação) das principais objeções levantadas contra esse tipo de mercado. Trata-se, portanto, de um modelo que regulamenta o mercado de órgãos de maneira ética, representando uma importante alternativa a ser analisada.

Arthur Matas (2006, p. 129-130) indica que um sistema viável de regulação de órgãos deve se pautar em alguns princípios básicos: (1) pagamento ao doador feito pelo governo ou por seguradoras; (2) alocação dos órgãos realizada por algum algoritmo predefinido; (3) avaliação integral do doador; (4) consentimento informado; (5) fiscalização; (6) acompanhamento de longa duração; (7) tratamento digno e respeitável para com o doador. Outro apontamento realizado pelo autor é a restrição desse sistema a uma determinada área geográfica, na medida em que somente assim é possível ter acompanhamento e fiscalização efetivos, bem como evita-se um turismo de órgãos.

Seguindo a mesma orientação, Charles Erin e John Harris (2003, p. 137-138) também apresentam um esboço de modelo de mercado regulado de órgãos. Esse mercado deveria ser restrito a uma única área geopolítica (e.g. Brasil, União Europeia). Assim, apenas cidadãos residentes nessa área estariam aptos a vender seus órgãos. Haveria apenas um único comprador que compraria todos os órgãos e distribuiria de acordo com uma concepção justa de prioridade médica. Desse modo, não haveria compras e vendas diretas. Os órgãos deveriam ser avaliados para assegurar um rígido controle de qualidade. Os preços deveriam ser altos o bastante para atrair os potenciais vendedores. Seguindo esses parâmetros, Erin e Harris acreditam que possa ser estabelecido um mercado ético de órgãos humanos.

O caso do Irã representa a aplicação de um modelo ético e regulado do mercado de órgãos. O grave problema da escassez de órgãos levou esse país a implementar, em 1988, um programa de doação renal compensado e regulado. O resultado foi surpreendente: em 1999 não havia mais lista de espera para transplantes renais. Até o fim de 2005, um total de dezenove mil seiscentos e nove transplantes renais haviam sido realizados. (GHODS; SAVAJ, 2006, p. 1137).

Importante analisar quais são as características desse modelo. O primeiro passo do procedimento é uma avaliação pelo médico em que são discutidas as vantagens da doação realizada por parentes, bem como o problema da escassez de órgãos provenientes de doadores falecidos no país. Caso o paciente não tenha nenhum parente vivo disposto a doar, procede-se o encaminhamento para a Associação de Paciente para Diálise e Transplante (DATPA) com a finalidade de encontrar um doador de órgãos vivo e sem parentesco. Os doadores voluntários também entram em contato com a associação para manifestar sua vontade. Importante destacar que

\footnotetext{
${ }^{9}$ Uma opção que merece estudo é a comercialização de órgãos das pessoas falecidas. Em apertada síntese, esse mercado seria pautado por uma remuneração à família do falecido que doasse seus órgãos após a morte. Essa possibilidade é interessante pois vol.10, no. 01, Rio de Janeiro, 2017.pp. 434-453 
essa associação é formada por pacientes com doenças renais em estágio terminal e não recebem nenhum incentivo para fazerem esse trabalho. Consequentemente, não existe espaço para agências ou corretores nesse modelo, já que todo o trabalho de intermediação é feito por essa associação. ${ }^{10}$ As equipes de transplante renal são todas pertencentes a hospitais universitários e o governo paga todas as despesas hospitalares para o transplante renal. Depois de realizado o transplante, o doador recebe uma recompensa e um seguro de saúde do governo. O doador também recebe uma recompensa (rewarding gift) do receptor - providenciado e definido pela associação antes da doação. Se o receptor não tiver condições de dar esse presente, organizações de caridade cumprem esse papel. O governo também disponibiliza todos os medicamentos essenciais a preços subsidiados e reduzidos nesse ponto as organizações de caridade também possuem um papel relevante. A equipe de transplante não recebe nenhum incentivo do governo ou do receptor. Por fim, importante destacar dois pontos: o primeiro é o fato do programa não ser permitido para estrangeiros, com a finalidade de se evitar o turismo de órgãos; o segundo é que todo o procedimento é rigorosamente fiscalizado pela Sociedade Iraniana para Transplante de Órgãos. Dessa maneira, os padrões éticos são levados à sério. (GHODS; SAVAJ 2006, p. 1137-1138).

Um modelo ético e regulado de mercado de órgãos, tal como delineado ao longo desse ponto, pode ser uma alternativa a ser levada em consideração no combate ao tráfico de órgãos. A razão é clara: esse modelo potencializa os argumentos favoráveis e enfraquece os contrários ao mercado regulado de órgãos. Por um lado, há o aumento da quantidade de enxertos disponíveis para transplante, a diminuição do tráfico de órgãos e um fortalecimento da autonomia. Por outro, o argumento da exploração é atenuado ao se estabelecer um único comprador e uma fiscalização efetiva. Também não pode prevalecer o argumento da injustiça ao se estabelecer um modelo equânime de distribuição de órgãos. Os argumentos do dano e de um consentimento viciado também são minimizados pela avaliação e pelo acompanhamento de longo termo ao doador. Por fim, o que resta são argumentos de caráter metafísico, tal como a sacralidade do corpo e a objetificação do ser humano. O grande questionamento a se fazer é: tem como se falar em uma metafisica em uma sociedade cada vez mais plural? E mais, é correto justificar a proibição de um mercado regulado e ético com base nesse tipo de argumentação?

\section{CONCLUSÃO}

Ao longo do artigo procurou-se investigar a possibilidade de um mercado regulado e ético de órgãos como meio de combate ao tráfico - prática cada vez mais recorrente e abrangente em um contexto globalizado. Para tanto, foram estudados os principais argumentos favoráveis e contrários à mercantilização de órgãos. Buscouse uma argumentação livre de pré-conceitos e aberta ao melhor discurso. O tema é complexo, o percurso é

elimina diversas objeções levantadas contra um comércio em vida de órgãos (e.g. dano, risco, consentimento, exploração). Essa possibilidade será estudada em outra oportunidade.

${ }^{10}$ Em 2006 haviam 302 unidades de diálise, 25 centros de transplante e 79 escritórios da DATPA em todo o país. 
tortuoso, e a conclusão não segue orientação distinta.

A resposta, ainda que transitória, parece residir na equação envolvendo as vantagens e as desvantagens de um mercado regulado de órgãos. Qual dessas deverá prevalecer no discurso? Parece certo que não há, nessa questão, uma solução absoluta. As vantagens se mostraram objetivas e diretas. $\mathrm{O}$ aumento na quantidade de órgãos para transplante e o enfraquecimento do tráfico são questões pragmáticas e empíricas, ao passo que a autonomia é um contundente argumento moral e jurídico. Exploração, objetificação, consentimento defeituoso, injustiça distributiva e a santidade do corpo são argumentos robustos que atacam diversas facetas da mercantilização dos órgãos.

Sem sombra de dúvidas, todos os aspectos levantados possuem relevância e afetam um possível veredito sobre o mercado regulado de órgãos. Contudo, nesse incessável balanço argumentativo, uma solução se destacou. Se, por um lado, a criminalização do comércio de órgãos elimina por completo todas as objeções, também elimina os argumentos favoráveis. Parece uma solução extrema que, apesar de todo esforço jurídico, ético e social, não tem atingindo de maneira satisfatória seu principal objetivo, qual seja, a eliminação do tráfico de órgãos. Por outro lado, um mercado de órgãos regulado e ético, tal como delineado ao longo desse artigo, pode ser uma alternativa interessante, na medida em que enfraquece (ou elimina) as principais objeções a esse mercado, bem como fortalece os benefícios.

As consequências da regulamentação de um mercado ético de órgãos ainda são, de certa forma, incertas. Isso ocorre em razão da escassez de situações empíricas de aplicação desse mercado - apenas o Irã adotou políticas nesse sentido. Assim, a contribuição desse artigo é no sentido de entender que o mercado regulado e ético de órgãos pode ser uma alternativa viável para o problema do tráfico de órgãos, tanto em termos morais, quanto em termos jurídicos - ainda que seja uma proposta de lege ferenda.

Não obstante, uma reflexão persiste. Michael Sandel, em O que o dinheiro não compra, indaga em que tipo de sociedade se vive e que tipo de sociedade se quer viver. Ora, vive-se em uma sociedade de consumidores, onde tudo - ou quase tudo - está à venda. Não obstante, esse é o tipo de sociedade em que se quer viver? A comodificação de tudo e todos é um processo irreversível? São questões perturbadoras.

Ao refletir sobre o assunto, todavia, percebe-se que a discussão não gira apenas em torno do dinheiro, da mercantilização, do mercado pelo mercado. Subjaz a todo esse debate uma questão muito mais importante: a preservação de vidas humanas. Todos os anos morrem milhares de pessoas devido à escassez de órgãos. Nesse sentido, um mercado regulado e ético de órgãos humanos apresentou-se uma alternativa viável para o combate ao tráfico de órgãos. 


\title{
REGULATED MARKET OF ORGANS: A POSSIBILITY AGAINST TRAFFICKING?
}

\begin{abstract}
The human organ trafficking is a global concern. The principal manner of combating this practice has been its criminalization. Despite the juridical efforts, trafficking has increased its range by promoting a profitable black market that has as centrality the exploitation of people in a vulnerable situation. The organ scarcity together with the prohibition of the body parts commercialization are the major factors for the trafficking rising. Thus, it is necessary to investigate the possibility of a regulated, licit and ethical market in human organs. A market that increases the supply of available organs for transplantation and thus weakens the organ trafficking. Therefore, from a literature review, the main moral arguments for and against this type of market will be analyzed. Still, proposed regulatory models will be studied, especially the current in Iran. The conclusion indicates that a regulated and ethical market of organs may be a possible alternative to combat trafficking.
\end{abstract}

Keywords: Regulated Organ Market; Organ Trafficking; Human Body Commodification; Bioethics; Biolaw.

\section{REFERENCIAS}

BAUMAN, Zygmunt. Vida para consumo: a transformação das pessoas em mercadoria. Rio de Janeiro: Zahar, 2008.

CARNEY, John. A Human Harvest: China's organ trafficking exposed in shocking documentary that alleges the illegal trade is now worth a staggering US\$1 billion a year. Daily Mail. 6 abr. 2015.

CONSEJO DE EUROPA. Convenio del Consejo de Europa sobre la lucha contra el tráfico de órganos humanos. 2014.

DWORKIN, Gerald. Market and Morals: The case for organ sale. In: Morality, Harm and the Law. Westview, 1994.

ERIN, Charles A; HARRIS, John. An ethical market in human organs. J Med Ethics 2003; 29: 137-138.

ESPAÑA. Código Penal y legislación complementaria. Ministerio de Justicia, 2016

FLEISCHACKER, Samuel. A short history of distributive justice. Cambridge: Harvard Press, 2004.

GHODS, Ahad J.; SAVAJ, Shekoufeh. Iranian model of paid and regulated living-unrelated kidney donation. Clin JAm Soc Nephrol 1: 1136-1145, 2006.

KANT, Immanuel. Fundamentação da metafísica dos costumes. Lisboa: Edições 70, 2007.

LARA, Mariana Alves et al. Um mercado lícito como alternativa para o problema da escassez de órgãos e tecidos desafios e proposta. In: Asociación de Universidades del Grupo Montevideo (Org.). XIX Jornadas de Jóvenes Investigadores de la Asociación de Universidades del Grupo Montevideo. Ciudad del Este: 2011.

MACKEEY, Ejan; ROSSEAU, Stéphane. Análise econômica do direito. 2. ed. São Paulo: Atlas, 2015. 
MAGALHÃES, José Luiz Quadros de. Estudo prévio: a morte. In: Maria de Fátima Freire de Sá; Diogo Luna Moureira. Autonomia para morrer. 2. ed. Belo Horizonte: Del Rey, 2015.

MATAS, Arthur J. Why we should develop a regulated system of kidney sales: a call for action. Clin J Am Soc Neprhol 1:1129-1132, 2006.

NELKIN, Doroth; ANDREWS, Lori. Homo Economicus: commercialization of body tissue in the age of biotechnology. Hasting Center Report: 28, n. 5, 1998: 30-39.

OLIVEIRA, Lucas Costa de. Reflexões sobre o princípio da autonomia privada. In: Leonardo Macedo Poli; Fernanda São José. (Org.). Direito Civil na contemporaneidade. Belo Horizonte: D'Plácido, 2016.

OLIVEIRA, Lucas Costa de. Seriam os direitos da personalidade mercadorias? Reflexões sobre a existência de um mercado de direitos existenciais. In: Direito Civil Contemporâneo II. Florianópolis: CONPEDI, 2015.

RIPPON, Simon. Imposing options on people in poverty: the harm of a live donor organ market. J Med Ethics, 2014; 40: 145-150.

RODOTÀ, Stefano. La vida y las reglas: entre el derecho y el no derecho. Madrid: Editorial Trotta, 2010.

SÁ, Maria de Fatima Freire de; NAVES, Bruno Torquato de Oliveira. Manual de Biodireito. 3 ed. Belo Horizonte: Del Rey, 2015.

SANDEL, Michael. O que o dinheiro não compra: os limites morais do mercado. Rio de Janeiro: Civilização Brasileira, 2014.

SAVULESCO, Julian. Is the sale of body parts wrong? J Med Ethics, 2003; 29: 139-140.

SCHEPER-HUGHES, Nancy. Human traffic: exposing the brutal organ trade. New Internationalist: May 2014.

SINGER, Peter. Altruism and Commerce: a defense of Titmuss against Arrow. Philosopy and Public Affairs. Vol. 2,n. 3, 1973; p. 312-320.

TITMUSS, Richard. The gift relationship: from human blood to social policy. New York: The New York University Press, 1997.

VILLELA, João Baptista. Direito, Coerção \& Responsabilidade: por uma ordem social não-violenta. Belo Horizonte: Faculdade de Direito da UFMG, 1982.

WILKINSON, Stephen. Bodies for sale: ethics and exploitation in the human body trade. New York: Routledge, 2003.

Trabalho enviado em 16 de março de 2016.

Aceito em 16 de julho de 2016. 